\title{
A DESORDEM FUNDIÁRIA NO BRASIL: ANÁLISE A PARTIR DAS ORIGENS DO PROBLEMA
}

\section{LAND DISORDER IN BRAZIL: AN ANALYSIS OF THE ORIGINS OF THE PROBLEM}

\author{
Paulo Afonso Cavichioli Carmona ${ }^{1}$ \\ Fernanda Loures de Oliveira²
}

RESUMO: Revisitando-se a forma de ocupação histórica do Brasil, mediante olhar comprometido e científico, a partir do exame de pesquisa analítico-significante, promove-se uma análise das vicissitudes da colonização do território brasileiro por Portugal. Demonstra-se que o método essencialmente exploratório e extrativista de ocupação, pautado na apropriação dos recursos e conhecimentos dos naturais da terra, e na desconsideração de seus direitos de posse, é parte da explicação sobre a atual confusão territorial brasileira. Ressalta-se, igualmente, como um dos fatores para a explicação do problema, o modo de constituição histórica de posses e propriedades, com altos índices de concentração de terras e estímulo ao apossamento irregular. Finalmente, apresentase a ocupação voltada à extração de recursos naturais como uma das causas da formação dos núcleos populacionais desordenados, o que possui relevantes reflexos para os problemas urbanísticos atuais.

PALAVRAS-CHAVE: Ocupação histórica do Brasil; Método exploratório de ocupação; Constituição histórica de posses e propriedades; Formação dos núcleos populacionais.

ABSTRACT: This study provides a review of the characteristics of land occupation over time to analyze the vicissitudes of Portugal's colonization of Brazilian territory, through thorough and scientific consideration and examination of the relevant analytical research. We demonstrate that the essentially exploitative and extractive nature of occupation, rooted in appropriation of the natural resources and knowledge of the territory's native inhabitants and disregard for their possessory rights, offers a partial explanation for Brazil's current territorial disarray. However, equally important, in our view, is the historical constitution of possession and ownership in Brazil, marked by high levels

\footnotetext{
${ }^{1}$ Professor Titular do Programa de Mestrado e Doutorado em Direito do Uniceub; mestre e doutor em Direito pela PUC-SP; Juiz de Direito (TJDFT); Professor dos cursos de especialização em Direito da FESMPDFT. Brasil. Email: paulo.carmona@uniceub.br

2 Mestre em Direito e Políticas Públicas pelo Centro Universitário de Brasília. Registradora de Imóveis do 8o Ofício de Registro de Imóveis do Distrito Federal. Brasil.E-mail: floures.direito@gmail.com
} 
of land concentration and incentives to irregular land appropriation. Finally, we argue that land occupation based on the extraction of natural resources constitutes an underlying cause for the rise of disorganized population centers, with a significant impact on current urban planning efforts.

KEYWORDS: Historical occupation of Brazil; Exploitative nature of land occupation; Historical constitution of possession and ownership; Formation of population centers.

\section{SUMÁRIO}

INTRODUÇÃO 608

1 A OCUPAÇÃO DO TERRITÓRIO NACIONAL: entre a apropriação e a exploração 609

2 POSSE E PROPRIEDADE: a desconsideração dos direitos indígenas.

3 OS NÚCLEOS POPULACIONAIS E A EXTRAÇÃO DE RECURSOS NATURAIS

CONSIDERAÇÕES FINAIS

REFERÊNCIAS

INTRODUÇÃO

O presente trabalho destina-se a examinar a forma de ocupação histórica do território nacional pelos portugueses, bem como o regime de colonização essencialmente exploratório e extrativista como parte da justificativa para a ainda existente confusão territorial brasileira.

Pretende-se demonstrar que a expansão da ocupação do território nacional não se deu de modo planejado e ordenado, mas de forma açodada, destinada a exploração de recursos naturais, com pouca ou nenhuma preocupação sobre o assentamento organizado destinado ao povoamento.

O estudo é relevante como forma de viabilizar o adequado diagnóstico da irregularidade fundiária, procedimento necessariamente prévio a qualquer tentativa de elaboração de uma solução jurídica para o problema. Nesse sentido, é apto a auxiliar o desenvolvimento do Direito, especificamente, no campo fundiário e de políticas urbanas de regularização.

Utiliza-se como metodologia de pesquisa o exame analítico-significante, extraindo-se interpretações permitidas dos elementos históricos e das inúmeras variáveis estruturais. Afasta-se, portanto, a abordagem causal-analítica, inapta a explicar o comportamento social e as vicissitudes históricas de uma estrutura. Nessa linha, não se supõe a determinação mecânica e imediata, em relação de "causa-efeito", entre o modo de colonização do Brasil e a atual desordem fundiária do território nacional, sendo este apenas um dos elementos a serem considerados (CARDOSO, 1975, p. 23). 
Portanto, o olhar histórico é datado e localizado, de modo a evitar a fundamentação equivocada de que todos os problemas atuais são necessariamente consequência do modo de colonização portuguesa, pois, como mencionado, nem sempre é possível traçar essa relação de causalidade. Ademais, não se pretende ler o passado a partir do que acabou por acontecer, de modo a encontrar prenúncios do que de fato ocorreu (HESPANHA, 1945, p. 20).

Ainda sob o ponto de vista metodológico, vale pontuar que a tecnologia de construção da verdade jurídica é uma tecnologia de poder e não de verdade ou de justiça (FOUCAULT, 2002, p. 18). A partir dessa ótica é que se examina a história da composição da propriedade privada imobiliária no Brasil, sobretudo, a partir do estudo da gênese dos direitos de propriedade.

Inicia-se este trabalho pela análise do modo de ocupação nacional, demonstrando-se que a apropriação e a exploração foram as medidas que direcionaram a colonização portuguesa. Em seguida, passa-se para o exame da determinação histórica da propriedade e do modo pelo qual esse processo desconsiderou os direitos de posse do povo indígena. Por fim, será abordada a questão da formação dos núcleos populacionais, a qual não foi direcionada a partir da constituição de uma adequada estrutura de ocupação, mas sob a ótica exploratória e de extração de recursos naturais.

\section{1 - A OCUPAÇÃO DO TERRITÓRIO NACIONAL: entre a apropriação e a exploração}

O Brasil, a exemplo das colônias tropicais de modo mais geral, não teve sua ocupação constituída, como nas zonas temperadas ${ }^{3}$, mediante colônias de povoamento, mas com o intuito extrativista e de exploração, no âmbito do comércio europeu (PRADO JÚNIOR, 1979, p. 22 e 30). De fato, Leroy-Beaulieu esclarece que existem três tipos básicos de colônia: as colônias de exploração; as colônias de povoamento; e as mistas (LEROY-BEAULIEU, 1882, p. VII).

Inicialmente, as colônias de povoamento são caracterizadas pela considerável imigração (LEROY-BEAULIEU, 1882, p. VII) de pessoas que não buscavam "fazer a América", mas fugir das lutas político-religiosas europeias, com o intuito de "reconstruir um lar desfeito ou ameaçado". Tais pessoas, pelas razões que as movia, procuravam áreas dotadas de condições naturais semelhantes às da Europa e, por isso, deslocavam-se para as regiões da zona temperada (PRADO JÚNIOR, 1979, p. 26). Nesses locais, embora as terras fossem inferiores às colônias dos trópicos, a liberdade de

\footnotetext{
${ }^{3}$ Área compreendida entre os trópicos e os círculos polares. No sentido atribuído ao termo, vale lembrar das lendas geográficas da antiguidade que, até o século XV, com as descobertas marítimas, "dividiam a terra em cinco zonas, duas polares, duas temperadas e a tórrida" (trópicos), considerada inabitável. Entendiam-se como áreas que permitem a existência apenas as zonas temperadas, entretanto, alguns geógrafos excluíam dessas considerações "toda a região sul do Atlas, e outros levavam o seu exagero a considerar impossível a vida humana em todo o hemisfério austral” (FONSECA, 1908, p. 21 e 23).
} 
condução das atividades é uma das grandes causas de sua prosperidade, aliada à natureza das instituições políticas implantadas, mais favoráveis ao desenvolvimento e ao cultivo da terra. Outro fator a ser considerado é o entrave à apropriação de terras não cultivadas, o que dificultou a manutenção de grandes latifúndios nas mãos de poucos, favorecendo o caráter mais equitativo da distribuição de terras (SMITH, 1996, p. 70-71).

Por outro lado, as colônias de exploração, implantadas nos trópicos, pela dupla influência da escravidão e do pacto colonial, foram direcionadas ao cultivo de produtos destinados à exportação, sem preocupações com a constituição de sociedades: o absenteísmo dos proprietários, a inexistência das classes médias e a opressão de uma vasta quantidade de pessoas, desprovidas de direitos, em prol da exploração excessiva da terra, em torno, muitas vezes, de um único produto, foi o que ditou o ritmo da ocupação (LEROY-BEAULIEU, 1882, p. 197).

A exploração sistemática de recursos, inicialmente opulentos, ensejou o gasto da terra e o despovoamento da caça, bem como a transferência das moradas das populações primitivas, para escapar ao aniquilamento (HOLANDA, 1994, p. 70). O que moveu a colonização estrangeira no Brasil foi, assim, essencialmente a cobiça (PRADO, 1981, p. 54-61):

As entradas pioneiras ou de resgate, abrindo-se em leque das costas marítimas em diferentes diretrizes à procura dos sertões, formaram o grande processo de exploração e povoamento que é a própria história do país. Martius aconselha a quem a quiser, a divisão em grupos das antigas capitanias, separando a natureza física os vários territórios da colônia. Assim, converge a história de São Paulo, Minas, Goiás e Mato Grosso; a do Maranhão se liga à do Pará, e à roda de Pernambuco formam um grupo natural o Ceará, Rio Grande do Norte e Paraíba; a história da Bahia é finalmente a de Sergipe, Alagoas, Porto Seguro e de parte do Piauí e Maranhão. [...]

Apesar do desenvolvimento agrícola em certas capitanias, culminando com várias vicissitudes na exploração pernambucana e baiana da cana-de-açúcar e concomitantemente com o estabelecimento dos currais de gado - o Brasil foi, entretanto, na lenda e na realidade, o país do ouro e das pedras preciosas.

Como será analisado nas linhas seguintes, a ânsia pela mineração foi o que deu azo a diversos

núcleos populacionais, predecessores de nossos atuais centros urbanos. Trata-se, porém, de efeito apenas lateral, já que a exploração dos trópicos não se processou mediante empresa metódica e racional ou de uma vontade "construtora e enérgica", mas foi operada com "desleixo e certo abandono" (HOLANDA, 1995, p. 43).

Ao enviar para a colônia "os elementos irrequietos do povo sem cultura e sem piedade", Portugal assentou "as raízes da nossa história econômica sobre a cobiça da riqueza fácil, na mineração e na devastação das matas, com a submissão do indígena e a escravização do africano" (TORRES, 1978, p. 100). A irresponsabilidade na ocupação do território é só mais um elemento nesse contexto. 
A empresa simplesmente espoliativa e extrativa dá lugar à ocupação econômica do território brasileiro apenas como consequência da pressão política exercida pelas demais nações europeias sobre Portugal, sob o argumento de que os portugueses não teriam direito às terras que não houvessem ocupado. Da fácil extração de metais preciosos, passa-se, assim, à exploração agrícola das terras brasileiras (FURTADO, 2007, p. 26-29). Há, pois, o deslocamento da base da colonização da pura extração de "riqueza mineral, vegetal ou animal - o ouro, a prata, a madeira" etc., para o desenvolvimento de riqueza local, por meio da agricultura, da sesmaria ${ }^{4}$, e, enfim, da grande lavoura escravocrata (FREYRE, 2003, p. 79).

No entanto, não foi uma típica civilização agrícola o que os portugueses instauraram no Brasil com a lavoura açucareira. O que os colonizadores vinham buscar "era, sem dúvida, a riqueza, mas riqueza que custa ousadia, não riqueza que custa trabalho", a mesma que obtinham na Índia, com especiarias e metais preciosos. Assim, os lucros obtidos com a plantação de cana e a fabricação de açúcar para mercados europeus compensaram, de início, o esforço - de mãos e pés negros -, "mas era preciso que fosse muito simplificado, restringindo-se ao estrito necessário às diferentes operações" (HOLANDA, 1995, p. 49).

As origens de nossa formação colonial não foram propícias, portanto, ao desenvolvimento de aptidões políticas e de organização do território. O Brasil representava para a corte de Lisboa apenas uma fonte de riqueza a ser economicamente explorada e quando, finalmente, a Metrópole cogitou de organizar a colônia, "o processo das capitanias adotado por D. João III enquadrava-se rigorosamente na ideia formulada mais de um século antes pelo Infante D. Henrique para a exploração comercial da África" (AMARAL, 2014, p. 6).

Do mesmo modo, a divisão do território em províncias também foi determinada por critério quase exclusivamente financeiro, baseado na "conveniência de utilizar-se com a maior eficácia possível das riquezas do Brasil". Por consequência, "durante mais de dois séculos a situação das populações distribuídas pelo território já ocupado" foi, nitidamente, a de "simples colonos empenhados em aproveitar as riquezas naturais do país, sem quaisquer preocupações sérias de constituírem uma coletividade coordenada" (AMARAL, 2014, p. 6-7).

No entanto, nem tudo se resume à exploração. Há outro movimento, igualmente relevante, que direcionou a atuação portuguesa no Brasil: a apropriação. A propósito, a primeira não seria possível sem a segunda.

\footnotetext{
${ }^{4}$ Regime de divisão de terras incultas, concedidas para sua adequada utilização, mediante renda estipulada, "geralmente, na sexta parte dos frutos", sob pena de reversão à Coroa (LIMA, 1990, p. 19-22).
} 
Com efeito, a forma de ocupação do território brasileiro por Portugal foi marcada pela apropriação do conhecimento e dos recursos dos nativos da terra, embora se tenha construído uma visão histórica, claramente equivocada, de que o povo indígena seria despreparado e que todos os recursos utilizados para a ocupação e exploração do Brasil eram genuinamente portugueses. Construiu-se, pois, uma visão racialista pela qual se afirmou não apenas a existência de diferentes raças, como também a crença de que a dos lusitanos seria superior a dos naturais da terra, embora os primeiros tenham admitido, em grande parte, soluções da cultura indígena, o que demonstra o não etnocentrismo da ocupação portuguesa (TODOROV, 1993, p. 21 e 110).

Nada obstante a visão do povo indígena como selvagens aptos à civilização (SCHWARCZ, 1993, p. 111-113), em quase tudo, os adventícios precisaram habituar-se às alternativas e recursos dos primitivos habitantes da terra, como ao seu sistema de viação, cujo traçado ainda parece concordar, no essencial, com muitas estradas de ferro. A marca dos "selvagens" não representou de modo algum uma herança desprezível, mas constituiu elemento fecundo e positivo. Nesse sentido, pode-se dizer que a influência indígena é que tornou possíveis "as grandes empresas bandeirantes" (HOLANDA, 1994, p. 19-21 e 26), até porque o português "mais puro", fixado como senhor de engenho, tendia à estabilidade, em contraste com o índio e o mestiço de índio com português mais tendente à mobilidade (FREYRE, 2003, p. 42-43).

Aos índios tomaram também os portugueses "instrumentos de caça e pesca, embarcações de casca ou tronco escavado, que singravam os rios e águas do litoral, o modo de cultivar a terra ateando primeiramente fogo aos matos" (HOLANDA, 1995, p. 47), além de muitos outros recursos. Apropriaram-se também de importantes informações. De fato, os índios eram dotados de extraordinária habilidade cartográfica, havendo quem dissesse que seus desenhos não eram inferiores aos de cartógrafos europeus do período medievo. Representavam até a menor irregularidade no curso de um rio nessa rústica geografia. Nada disso é compatível, por certo, com as generalizações ainda existentes sobre a "mentalidade primitiva" (HOLANDA, 1994, p. 23-24).

O indígena concorreu, ainda, para a exploração do interior, pela prospecção de metais e pedras preciosas (PRADO JÚNIOR, 1979, p. 37). Os depoimentos dos índios faziam presumir regiões que comportavam abundantes jazidas de metais preciosos. Assim, passou-se a entrar terra adentro a fim de descobrir as minas que os índios relatavam haver (HOLANDA, 2000, p. 43-44), interiorizando a ocupação com vistas à exploração aurífera.

Do mesmo modo, "muito alimento que pareceria repugnante a paladares europeus teve de ser acolhido" pelos colonos brancos. Mais transigentes que o gentio da terra, os colonos passaram a adotar os recursos e táticas dos índios para aproveitar o mundo animal e vegetal, acomodando-se "à dieta alimentar dos primitivos moradores do país" (HOLANDA, 1994, p. 56). 
Do exposto, é fácil concluir que o modelo de ocupação do território brasileiro pautou-se, pois, pela apropriação dos recursos e da sabedoria indígena e pela intenção de exploração do território, inicialmente, voltada à extração e, em seguida, à lavoura escravocrata. Nenhuma preocupação houve com a ordenação e a organização dos núcleos populacionais, formados com desleixo e abandono.

\section{2 - POSSE E PROPRIEDADE: a desconsideração dos direitos indígenas}

Embora, como visto, as soluções indígenas tenham sido muito importantes para a colonização portuguesa do Brasil, pois seus conhecimentos geográficos e de recursos naturais foram apropriados pelos conquistadores, os naturais da terra tiveram seus direitos de posse absolutamente desconsiderados pela Metrópole. Assim, a divisão das terras nacionais foi feita sem qualquer consideração pelas terras historicamente ocupadas pelos índios.

Deveras, durante os três inaugurais e fragosos séculos da história do Brasil, a partir das primitivas feitorias - instituídas em vários pontos da costa nacional, como decorrência da expedição de Américo Vespúcio (1501 e 1503) destinada à análise completa do território descoberto - vigorou o sistema de capitanias, sistema de colonização deflagrado por D. João III, que perdurou até a abertura dos portos brasileiros ao comércio externo e a constituição do Brasil em reino. Esse modo de gestão territorial, concebido em 1532, repartiu as terras brasileiras entre poderosos capitalistas do reino, que assumissem os gastos da colonização, mediante cartas de doação, que fixavam a legitimação das posses, os direitos e apanágios dos beneficiados; e forais, "contracto emphyteutico, em virtude do qual se constituiam perpetuos tributarios da corôa, e dos donatarios capitães móres, os solarengos que recebessem terras de sesmarias" (MARTINS JÚNIOR, 1895, p. 157-163).

Essa forma de administração territorial, na visão de Amaral, foi fracassada e contribuiu para o não desenvolvimento de modos eficazes de organização política e ocupacional do território brasileiro (AMARAL, 2014, p. 6):

O fracasso desse sistema, dando lugar dezesseis anos mais tarde ao estabelecimento do Governo Geral na Baía, ainda obedeceu a planos econômicos de exploração das riquezas minerais que se julgavam existir no interior do continente e para cujo aproveitamento se compreendia agora ser necessário desenvolver uma ocupação muito mais ampla, envolvendo naturalmente operações militares e exigindo, portanto, maiores cuidados com os aspectos políticos da colonização do Brasil. [...]

O fato que desejamos fixar e acentuar é que as origens de nossa formação colonial foram de molde a não permitir o desenvolvimento precoce de aptidões políticas, que facilitassem aos colonos promover experiências frutíferas, no sentido do estabelecimento de instituições e de métodos de 
governo em harmonia com as realidades do ambiente onde ia surgindo a estrutura embrionária da futura nacionalidade brasileira.

Como visto, o tipo de colono que procurou terras brasileiras era o empresário de grandes explorações rurais, por isso, as sesmarias representavam a concentração de latifúndios a nobres e fidalgos, avessos a regimes de exploração camponesa de pequenos proprietários (PRADO JÚNIOR, 1979, p. 120). Assim, pode-se dizer que "a obra política e comercial da colonização tinha como ponto de apoio a distribuição de terras", a partir do modelo legislado das sesmarias (FAORO, 2012, p. 146).

Essa normatização, de Dom Fernando I (provavelmente de 1375), embora não aplicada em terras lusitanas, teve seus princípios incorporados pelas Ordenações Afonsinas, Manuelinas e Filipinas, cuja efetivação se deu no Brasil. A distribuição dos chãos aráveis foi feita sem nenhum encargo, exceto o dízimo, com isenção de foro e de contribuição, respondendo o morador apenas pelo não cultivo; ademais, não havia liame entre o proprietário e a autoridade, salvo o de subordinação política, sem quaisquer vestígios feudais. Nesse contexto, "a largueza no distribuir provinha, também, do pouco valor das terras", cujo cultivo demandava certo número de escravos, "caros e difíceis depois que se desfez a ilusão do préstimo do indígena" (FAORO, 2012, p. 146-150).

Em suma, Freyre destaca que ficou a cargo da iniciativa particular, concorrendo às sesmarias, o povoamento e a defesa das "muitas léguas de terra em bruto que o trabalho negro fecundaria" (FREYRE, 2003, p. 80). A sesmaria, como método jurídico de vincular a terra à capacidade de cultivo consagrou as extensões latifundiárias. Por sua vez, a apropriação do solo em largas porções fez proliferar o dependente agrícola e criou uma classe de posseiros sem títulos (FAORO, 2012, p. 151).

Portanto, o sistema de ocupação era tendente à acumulação; à constituição de grandes proprietários de terras; não se ocupava dos direitos de posse indígenas; e tinha como pressuposto a concessão da exploração a capitalistas, dotados de recursos suficientes para o alto custo de exploração das terras concedidas. As sesmarias eram concedidas a fidalgos, com recursos suficientes para construir engenho, motivo pelo qual foram excluídas da terra as pessoas pobres e desfavorecidas, bem como se acabou por firmar o regime de "exploração rural em grande escala" (OLIVEIRA VIANNA, 1973, p. 68). Nessa linha:

Depois de perder o caráter administrativo que the fora infundido pelos legisladores de Portugal, para acentuar seu conteúdo dominial, o regime das sesmarias gera, ao contrário de seus propósitos iniciais, a grande propriedade. Para chegar a essas linhas de contorno, muito se deve ao influxo da escravidão e ao aproveitamento extensivo da pecuária, fatores que se aliam ao fato de que, para requerer e obter a sesmaria, era necessário o prévio prestígio político, confiada a terra, não ao cultivador eventual, mas ao senhor de cabedais ou titular de serviços públicos. A propriedade seria, desta sorte, uma afirmação aristocrática, para uma grande empresa ou para o domínio de lavradores e vaqueiros. [...]. 
O quadro está definido: a grande propriedade toma conta do país, com a dependência e o bloqueio de ascensão do lavrador não proprietário. A sesmaria não serve ao cultivo e ao aproveitamento, mas imobiliza o status do senhor de terras, utilizada menos em proveito da agricultura do que da expansão territorial, estimulada esta pelos agentes do rei no Brasil. O fim do regime das sesmarias estava, mesmo antes da Resolução de 17 de julho de 1822, decretado pelos fatos - a exaustão dos bens a distribuir fecha um período histórico (FAORO, 2012, p. 441-442).

Os índios não foram contemplados no sistema de sesmarias, embora suas trilhas tenham se prestado a determinar a localização de terras e a servir como pontos de referência; e suas armas o arco e a flecha - tenham servido como medida de distância, em substituição ao tiro de arcabuz (HOLANDA, 1994, p. 33 e 67). Somente com o alvará de 10 de abril de 1680, posto em vigor, após anos de esquecimento, pela Lei de 6 de junho de 1755, foi imposta norma de defesa dos ameríndios em face do sistema econômico dominante ("a latifundiária, monocultora e escravocrata"), resguardando-se seu livre uso de bens e áreas, já que eram os primeiros ocupantes e donos naturais das terras (FREYRE, 2013, p. 488-490). Em seguida, porém, a Constituição de 1824 omitiu qualquer referência à questão indígena e as legislações seguintes evidenciaram o descaso em relação aos direitos patrimoniais e territoriais dos índios (LOPES, 2006, p. 223).

Por meio da Resolução 76 de 17 de julho de 1822, foram interrompidas as concessões de sesmarias futuras, "até a convocação da Assembleia Geral, Constituinte e Legislativa" (BRASIL, 1887, p. 62-63), legitimando-se os posseiros sem títulos, com a qualidade de proprietários, por meio da anulação do regime de sesmarias (FAORO, 2012, p. 151). Posteriormente, foi outorgada a Constituição do Império de 25 de março de 1824, pela qual se consagrou o direito de propriedade e a abolição do confisco, no art. 179, caput e inciso XXII (BRASIL, 1824, Volume 1, p. 7). No entanto, o Brasil "permaneceu sem uma legislação que dispusesse a respeito da aquisição territorial no lapso temporal compreendido entre os anos de 1822 e 1850, interregno entre a suspensão do Regime das Sesmarias e o advento da Lei de Terras" (LOPES, 2006, p. 223).

A Lei de Terras - Lei 601 de 18 de setembro de 1850 - revalidou as sesmarias ou outras concessões do Governo Geral ou Provincial, que estivessem sendo efetivamente utilizadas (art. 4으); legitimou as posses mansas e pacíficas, adquiridas por ocupação primária, ou havidas do primeiro ocupante, que estivessem sendo utilizadas (art. 5o); fixou o conceito de terras devolutas, pertencentes ao Estado, como as que não se achassem aplicadas a uso público, não fossem domínio particular por qualquer título legítimo e não estivessem ocupadas (art. 3ㅇ); e determinou, no art. 1으, que a única forma de aquisição de terras devolutas seria pela compra (BRASIL, 1854, Volume 1, p. 10, pt. II).

Assim, a evolução do instituto das sesmarias chega ao termo final: "de concessão administrativa ao domínio, do domínio à posse, até o novo estatuto promulgado em 1850, que 
consagrou o sistema da compra das terras devolutas". Daí em diante, no lugar de benefícios públicos, a terra passa a ser adquirida por herança, doação, compra e, principalmente, pela ocupação (FAORO, 2012, p. 151 e 442). Para bem compreender a importância da ocupação, sobretudo, no período compreendido entre 1822 e 1850, vale lembrar as palavras de Cirne de Lima:

Apoderar-se de terras devolutas e cultivá-las tornou-se cousa corrente entre os nossos colonizadores, e tais proporções essa prática atingiu que pôde, com correr dos anos, vir a ser considerada como modo legítimo de aquisição do domínio, paralelamente a princípio, e, após, em substituição ao nosso tão desvirtuado regime das sesmarias.

Os dois processos chegaram a ter-se por equivalentes - "o método até 1822 usado para a distribuição das terras por meio das sesmarias e o que se tem empregado de então para cá por meio das posses".

Depois da abolição das sesmarias, então, a posse passou a campear livremente, ampliando-se de zona a zona, à proporção que a civilização dilatava a sua expansão geográfica.

Era a ocupação, tomando o lugar das concessões do Poder Público, e era, igualmente, o triunfo do colono humilde, do rústico desamparado, sobre o senhor de engenhos ou fazendas, o latifundiário sob o favor da metrópole.

A sesmaria é o latifúndio, inacessível ao lavrador sem recursos.

A posse é, pelo contrário - ao menos nos seus primórdios -, a pequena propriedade agrícola, criada pela necessidade, na ausência de providência administrativa sobre a sorte do colono livre e, vitoriosamente firmada pela ocupação (LIMA, 1990, p. 51).

Interessante notar a ascensão da ocupação irregular como solução frente à desigualdade na concessão regular de terras. A partir de um método comparativo sociológico (DUMONT, 2000, p. 7374), somente faz sentido falar em irregularidade fundiária se há uma ocupação regular e, no caso do regime de sesmarias, a excessiva concentração de terras nas mãos de poucos capitalistas foi justamente o que impulsionou a proliferação posterior do irregular.

Os dois instrumentos (sesmaria e posse), após o período de coexistência, concentraram-se na ocupação, como meio de pressão do lavrador humilde. Como a expulsão dos posseiros não era possível, diante dos riscos da revolução social fatalmente ocasionada, o remédio seria o reconhecimento da posse, efetivado em 1850 (FAORO, 2012, p. 443).

Para os índios, até então, nada havia sido garantido. Pelo contrário, o exame científico, na esteira de Bourdieu, apresenta que o poder simbólico mobilizado pela Coroa, até mesmo com a força do campo jurídico - titulações de sesmarias - (BOURDIEU, 1998, p. 7-12), afastou os indígenas de seu direito de acesso à terra, nem sempre reconhecido pelos adventícios.

A Lei de Terras objetivou organizar as áreas concedidas e regularizar ocupações, de modo a estabelecer o regime das terras devolutas pertencentes ao Estado. Atribuiu-se aos vigários católicos o controle das propriedades privadas, definindo-se as terras públicas por exclusão (AGHIARIAN, 2005, p. 67-68). Embora em seu art. 12 tenha regulado a questão indígena, prevendo a necessidade de reserva de terras devolutas "para a colonização dos indígenas", não havia qualquer menção à 
existência de um direito originário dos naturais da terra (indigenato) sobre os territórios que tradicionalmente ocuparam (LOPES, 2006, p. 223).

Após a proclamação da República, a Constituição de 1891 não fez qualquer referência ao povo indígena (BRASIL, 1891, p. 523). Somente com a Carta de 1934 houve a previsão, no art. 129, da necessidade de respeito "a posse de terras de silvícolas que nelas se achem, permanentemente localizados, sendo-Ihes, no entanto, vedado aliená-las" (BRASIL, 1934, Seção 1, Suplemento, p. 1). As Constituições de 1937 e de 1946 repetiram essas disposições, respectivamente, em seus arts. 154 (BRASIL, 1937, Seção 1, p. 22.359) e 216 (BRASIL, 1946, Seção 1, p. 13.059). O Texto Constitucional de 1967 acrescentou importantes contribuições, ao dispor que as terras ocupadas pelos índios se incluem entre os bens da União (art. 4으, inciso IV) e que é assegurada ao povo indígena "a posse permanente das terras que habitam e reconhecido o seu direito ao usufruto exclusivo dos recursos naturais e de todas as utilidades nela existentes" (BRASIL, 1967, Seção 1, p. 953). Prosseguindo, a Emenda 1 de 1969, além de reiterar as disposições da Carta de 1967, acrescentou, em seu art. 198, $\S \S 1$ e e 2 o , "a nulidade e a extinção dos efeitos jurídicos de qualquer natureza que tenham por objeto o domínio, a posse ou a ocupação de terras habitadas pelos silvícolas", sem que os ocupantes tenham direito a "qualquer ação ou indenização contra a União e a Fundação Nacional do Índio" (BRASIL, 1969, Seção 1, p. 8.865).

Finalmente, a atual Magna Carta reconhece aos índios "os direitos originários sobre as terras que tradicionalmente ocupam, competindo à União demarcá-las, proteger e fazer respeitar todos os seus bens" (art. 231); fixa como terras tradicionalmente ocupadas as habitadas em caráter permanente pelos indígenas, utilizadas em suas atividades produtivas e indispensáveis à preservação dos recursos naturais necessários ao seu bem-estar e à sua reprodução física e cultural ( $§ 1$ 1o); e estabelece a inalienabilidade e indisponibilidade das terras indígenas, bem como a imprescritibilidade dos direitos sobre elas incidentes. $O \S 60$ do art. 231 reitera a nulidade dos atos que tenham por objeto a ocupação, o domínio e a posse das terras indígenas, sem que haja direito a indenização ou a ações contra a União, ressalvado o custo de benfeitorias derivadas de posse de boa-fé.

O Decreto 1.775 de 8 de janeiro de 1996 é a norma que regulamenta o procedimento administrativo de demarcação de terras indígenas, por grupo técnico especializado designado pelo órgão federal de assistência ao índio. Conforme art. 2 ㄴ, $\S 10$, do referido diploma legal, os estudos destinados à demarcação terão natureza etno-histórica, sociológica, jurídica, cartográfica, ambiental e de delimitação fundiária.

Interessante notar que os conflitos relacionados às terras tradicionalmente ocupadas pelos índios são um problema contemporâneo. Nesse sentido, dois importantes precedentes foram 
firmados pelo Supremo Tribunal Federal (STF) a respeito do assunto, em 19 de março de 2009 (Petição 3.388 de Roraima) e em 9 de dezembro de 2014 (Agravo Regimental no Recurso Extraordinário com Agravo 803.462 do Mato Grosso do Sul) - datas bastante recentes.

Conforme o critério concebido pelo STF, consideram-se terras tradicionalmente ocupadas pelo povo indígena as por eles habitadas na data de promulgação da Constituição Federal de 1988, estabelecida como marco temporal para esta definição; desde que existente relação efetiva do povo com as terras, de modo a caracterizar a tradicionalidade da ocupação (BRASIL, 2009, p. 41-43). No entanto, em caso de "renitente esbulho" - caracterizado pelo "efetivo conflito possessório que, mesmo iniciado no passado, ainda persista até o marco demarcatório temporal atual", isto é, a data da promulgação da Constituição, e materializado "por circunstâncias de fato ou, pelo menos, por uma controvérsia possessória judicializada" -, as áreas poderão ser consideradas terra indígena, ainda que, em 5 de outubro de 1988, os índios não as estivessem ocupando (BRASIL, 2015).

Por outro lado, se os índios habitaram a localidade, mas saíram por vontade própria ou foram expulsos em período anterior à vigência da atual Constituição Federal, não há que se falar em demarcação de terras, haja vista que, na interpretação do STF, "os incisos I e XI do art. 20 da Constituição Federal não alcançam terras de aldeamentos extintos, ainda que ocupadas por indígenas em passado remoto" (BRASIL, 2003, p. 3). Até mesmo porque, no início da história do Brasil, eram comuns as migrações indígenas e era fácil a constituição de novas moradas em territórios mais opulentos e terras menos gastas (HOLANDA, 1994, p. 70), o que teria o potencial de afetar ao uso indígena uma extensão muito elevada de terras, de modo desproporcional. Nesse sentido, é compreensível a delimitação perpetrada pelo STF.

Por todo o exposto, fica claro que o modo de definição dos direitos de posse e de propriedade fixado por Portugal favoreceu a excessiva concentração de terras em latifúndios constituídos em benefício de fidalgos portugueses e acabou por estimular o apossamento irregular, posteriormente regularizado pela Lei de Terras. Ademais, a divisão do território brasileiro em sesmarias concedidas pelo Governo Português, com a desconsideração dos direitos de posse indígenas - o que prosseguiu após a Independência do Brasil e ainda aflige as referidas comunidades, ante a omissão estatal na demarcação de suas terras (LOPES, 2006, p. 233) - contribuiu e ainda contribui para a proliferação de conflitos envolvendo posse e propriedade de terras brasileiras, influenciando na desordem fundiária ainda existente. 


\section{3 - OS NÚCLEOS POPULACIONAIS E A EXTRAÇÃO DE RECURSOS NATURAIS}

Embora, como visto, o modelo de ocupação nacional tenha sido essencialmente exploratório, e a constituição histórica das propriedades tenha feito tábua rasa de muitos direitos, certo é que a colonização portuguesa, em sua densidade histórica, a partir uma análise não compartimentalizada, mas construtiva (BERMAN, 2006, p. 10), acabou por também ensejar ocupações. Assim, foram constituídos núcleos populacionais, que deram origem aos atuais centros urbanos. Esse passado deve ser necessariamente levado em conta para o exame da questão fundiária das cidades atuais.

Deve-se destacar, desde logo, o caráter extraordinário da obra de ocupação portuguesa, que permitiu que o Brasil assumisse dimensões continentais, que não as pertenceria se assim não fosse. Trata-se de grande feito, pelo qual um "punhado de povoadores" foi capaz de promover a ocupação e a efetiva defesa de uma imensa área, de "oito e meio milhões de quilômetros quadrados", "contra pretensões aguerridas e exigentes de fortes rivais". É também surpreendente o fato de que, no período, a população portuguesa era tão insuficiente, que grande parte do próprio território de Portugal estava ainda, "em meados do séc. XVI, inculto e abandonado". Tal obra considerável foi, sem dúvidas, um "fator básico da grandeza futura do Brasil”; mas, igualmente, um ônus considerável sobre a colônia e, por conseguinte, sobre a nação, que "provocou esta disseminação pasmosa e sem paralelo que aparta e isola os indivíduos, cinde o povoamento em núcleos esparsos de contato e comunicações difíceis, muitas vezes até impossíveis" (PRADO JÚNIOR, 1979, p. 30 e 37).

Inicialmente, a ocupação do Novo Mundo foi restringida a pontos afastados na costa: "feitorias minúsculas que eram entrepostos de comércio dentro da primeira manifestação da existência econômica da terra - a exploração do pau-brasil" (BRUNO, 1967, p. 17). Os locais povoados, "conquistados à mata e ao índio", não passavam geralmente de "manchas dispersas, ao longo do litoral, mal plantadas na terra e quase independentes dela" (HOLANDA, 2000, p. 15). Com o tempo, os adventícios foram se concentrando na faixa litorânea, evidenciando "o caráter predominante da colonização: agrícola - donde a preferência pelas férteis, úmidas e quentes baixadas de marinha". Somente no segundo século tem início a penetração do povoamento para o interior (PRADO JÚNIOR, 1979, p. 39).

Foram diversos os tipos de expedição levadas a efeito no período colonial e que resultaram na exploração do território brasileiro e na dilatação de suas fronteiras. Nesse contexto, as bandeiras, expedições de iniciativa particular e destinadas a obtenção de lucros; e as monções, expedições fluviais paulistas, deflagradas pelo descobrimento das minas do Coxipó-Mirim, que partiam de Porto Feliz (HOLANDA, 1994, p. 135-136). Essa "colonização por enxames bandeirantes" intensificou-se em 
meados do séc. II até o começo do séc. IV, podendo ser distinguida em três períodos: o primeiro, do "ciclo do ouro de lavagem", o qual é litorâneo, com preponderância da influência oficial e "vai dos primeiros tempos da colonização" até a segunda metade do séc. II; o segundo, da "caça ao índio", inicia-se em "1562 e vai até 1696, com o seu clímax em 1628-80"; o terceiro, do "grande ciclo do ouro", principia em "1693, com a bandeira de Fernão Dias Paes", e vai até o fim do séc. III, caracterizando-se pela "grande e rápida expansão para os chapadões mineiros, goianos e matogrossenses" (OLIVEIRA VIANNA, 1973, p. 87).

Como visto, são similares as histórias de diversos estados brasileiros, podendo-se distinguir em grupos. A região Nordeste, por exemplo, teve seu território voltado, basicamente, à exploração da indústria açucareira, ressalvado o plantio de algodão no Maranhão, e do tabaco, em certas áreas de Pernambuco e de Alagoas. No entanto, a efetiva ocupação dos sertões, compreendidos, "a grosso modo, entre o Rio São Francisco e o Parnaíba", ocorreu de meados do séc. XVII a meados do XVIII, pela fixação de currais de gado, destinada a "atender ao crescente consumo de carne dos grandes mercados do litoral", desenvolvendo-se um conjunto de condições de edificação e vestuário diferentes do quadro cultural da costa, denominado civilização do couro (BRUNO, 1967, p. 27 e 7778). De outro lado, o extremo Norte brasileiro foi ocupado de meados do séc. XVII a meados do XVIII, em decorrência do "apresamento ou resgate de bugres, dessa forma incorporados à empreitada colonizadora", da extração de "drogas do sertão" e, em menor medida, para estabelecimento de lavouras e currais de gado (BRUNO, 1967, p. 45-46), sem contar a intervenção de outro fator de índole local: as missões católicas destinadas a catequizar o gentio (PRADO JÚNIOR, 1979, p. 37). Por sua vez, a ocupação do Sul "resultou da abertura do Caminho do Sul, da expansão dos paulistas e lagunenses interessados na indústria pastoril e no comércio de gado e do interesse do governo de Portugal em consolidar o seu domínio sobre a Colônia do Sacramento" (BRUNO, 1967, p. 71). A outro giro, no Centro-Oeste, a ocupação foi guiada pela descoberta de ouro, na primeira metade do séc. $\mathrm{XVIII}$, tendo como principal suporte a indústria mineradora, mediante a exploração aurífera e, em menor escala, de garimpo de diamante. No mais, o pastoreio e a lavoura foram esboçados apenas para o atendimento, ainda que insuficiente, das necessidades locais (BRUNO, 1967, p. 27). Igualmente, a história de Minas Gerais, caracterizada pela "internação do povoamento e a ocupação das terras montanhosas, em seguida à descoberta das jazidas de ouro", que "atirava os povoadores para brenhas distantes, permanecendo entre eles e os focos de origem o deserto", sendo tardio o povoamento das zonas intermédias (BRUNO, 1967, p. 49-50).

Assim, "converge a história de São Paulo, Minas, Goiás e Mato Grosso", pautada na ambição pela prata, pelo ouro e pelas pedras preciosas, que, por quase dois séculos foram apenas ilusões, confundindo-se, assim, as bandeiras de caça ao gentio em decorrência da esterilidade das bandeiras 
de mineração (PRADO, 1981, p. 55-56). De fato, o aprisionamento de índios e a busca por materiais preciosos foi o que moveu a exploração dos sertões brasileiros:

Os paulistas e mineiros foram os mais destemidos e audazes exploradores dos longinquos sertões do Brasil, attrahidos não só pela cobiça do ouro como pela conquista do braço hercúleo e barato do índio que elles perseguião para reduzirem á escravidão, abusando da lei que, nesse tempo, permitia o captiveiro dos índios, tomados em justa guerra e em certos casos especiaes (AZEVEDO, 1987, p. 38).

Encontrado o ouro, era pouco o tempo necessário para abater o mato cerrado. Também curto era o tempo que intermediava a notícia das arrobas de metal fornecidas e o êxodo e a chegada de população destinada à exploração das minas. Nessas condições, era difícil "tentar estabelecer qualquer ordem política e governo econômico", até mesmo em decorrência da distância e das dificuldades de comunicação (HOLANDA, 1994, p. 142-143).

Decerto, enquanto na América espanhola, o traçado dos centros demonstra o esforço de vencer a paisagem agreste, na América portuguesa, "a colônia é simples lugar de passagem, para o governo como para os súditos" (HOLANDA, 1995, p. 96-99). Embora esse imperfeito deslocamento tenha gerado, enfim, mais do que um "fortuito contato com o meio e com a gente nativa" (FREYRE, 2003, p. 79).

Ocorre que a internação do povoamento agravou o problema do poder de fato dos grandes proprietários rurais, enfraquecendo o poder das autoridades, o que tornou cada vez mais difícil "as possibilidades de se fazerem cumprir decisões de administração ou de justiça" (BRUNO, 1967, p. 79). Nesse sentido, pode-se concluir que não apenas a inexistência de qualquer sentido ordenador da ocupação contribuiu para a desorganização dos núcleos constituídos, como também a própria impossibilidade de sua implementação, ainda que houvesse alguma intenção nesse sentido por parte do Governo Central.

A distribuição de população no território colonial era fortemente irregular e, embora alguns núcleos tenham sido bastante densos, a separação uns dos outros era muito grande. $\mathrm{O}$ aspecto geral do povoamento "guardadas naturalmente as devidas proporções quantitativas, é mais ou menos o mesmo de hoje" (PRADO JÚNIOR, 1979, p. 36-37). É interessante notar, porém, que, mesmo diante de escassos elementos e das consideráveis distâncias entre os núcleos, foram efetivamente criados centros de povoamento estáveis no interior do território nacional, como é o caso de Cuiabá (HOLANDA, 1994, p. 149) e de diversos outros em Minas Gerais, Goiás e Mato Grosso. Afinal, "muitos paulistas deixaram-se ficar nas paragens do ouro, voltados para o amanho da terra", quando cessada a febre da mineração, "aí aplicando, nas sesmarias obtidas, o que lhes havia rendido a lavra" (LEITE, 1961, p. 166). 
Pode-se dizer que a colonização paulista do Mato Grosso é uma réplica do que se operou na colonização portuguesa do território brasileiro. Deu-se o pouco que se podia dar, uma vez que faltavam homens e recursos mesmo nos locais de origem. Ademais, a existência era fundada na economia extrovertida, gerando-se, isso sim, um "monstruoso e desordenado empreendimento capitalista", o qual é tão absorvente "que releva para um plano inferior o que não the possa servir imediatamente" (HOLANDA, 1994, p. 150). Nesse sentido, não houve mesmo qualquer tipo de preocupação com a organização dos núcleos formados:

De ocupação efetiva do interior, à parte o caso excepcional de São Paulo, plantado de início no planalto e arredado da costa, encontramos apenas a marcha progressiva das fazendas de gado no sertão nordestino e a lenta e escassa penetração da bacia amazônica. A dispersão pelo interior, intensa e rápida, é da primeira metade do séc. XVIII, quando o ouro, descoberto sucessivamente em Minas Gerais (último decênio do séc. XVII), Cuiabá, em 1719, e Goiás seis anos depois, desencadeia o movimento. Afluem então para o coração do continente levas sobre levas de povoadores (PRADO JÚNIOR, 1979, p. 39-40).

Mário Leite resume o móvel da migração paulista no desejo de "serem senhores e não senhoreados", em que pese o fato de que a fixação como agricultor ou criador não apaga a "assertiva de que o motivo dominante das incursões nas dobradas da Mantiqueira e no grande oeste tinha sido a conquista do ouro" (LEITE, 1961, p. 40). As terras assim ocupadas o foram com o fim preciso e previsto de obter pecúnia, relegando-se a um plano inferior tudo o que não pudesse servir diretamente a este propósito (HOLANDA, 1994, p. 150), a exemplo da organização dos núcleos formados. De outra parte, a migração dos mineiros deu-se com o intuito de obter "terras melhores que aquelas em que estavam labutando", inclusive por meio do apossamento, sendo muitas ainda sem dono, algumas devolutas "ou que poderiam ser adquiridas por um nonada" (LEITE, 1961, p. 4041).

Desse modo, fica demonstrado que a constituição dos núcleos populacionais brasileiros foi voltada à exploração da terra e à extração de recursos; a título de exemplo, é ilustrativo o caso da mineração aurífera no Mato Grosso, descrito por Sérgio Buarque de Holanda. A partir dessa perspectiva, fica patente a falta de preocupação dos adventícios com a organização territorial e a dotação de infraestrutura do território, o que gerou caos fundiário e desigualdade, em certa medida, ainda identificável na realidade brasileira atual.

\section{CONSIDERAÇÕES FINAIS}

Ao contrário das zonas temperadas, em que as instituições políticas implantadas foram mais favoráveis ao desenvolvimento econômico-social e a proibição à apropriação de áreas incultas 
equalizou a distribuição de terras, a formação colonial dos trópicos não foi propícia ao surgimento de aptidões políticas e de organização espacial, mas conduzidas a partir da exploração sistemática dos recursos, da grande lavoura escravocrata, da apropriação sistemática de alternativas e recursos dos povos indígenas e do esbulho de terras das populações primitivas.

Tais condições iniciais, somadas ao fato de que, durante mais de dois séculos, os colonos empenharam-se em aproveitar as riquezas locais e não em construir uma coletividade coordenada, formaram as bases de um futuro permeado de conflitos fundiários e dificuldades organizacionais.

Nesse contexto, o papel do Direito, como tecnologia de poder, tratou de compor a propriedade privada sob a nota das concessões do Poder Central, desconsiderando-se quaisquer relações de posse e uso pelos naturais da terra.

A Coroa Portuguesa arrogou-se o direito de proprietária do território brasileiro, bem como a prerrogativa de repartir as terras àqueles que se dispusessem a assumir os custos da colonização. Nesse sentido, o ponto de apoio da obra política lusitana foi a distribuição de terras, a partir do modelo legislado das sesmarias.

Deve-se ressaltar, entretanto, que as leis, no período, não serviram para excluir apenas os povos indígenas, mas também os pequenos posseiros e dependentes agrícolas, já que o instituto jurídico da sesmaria serviu, ao contrário de suas pretensões iniciais, à consagração de grandes extensões latifundiárias, de exploração rural em larga escala.

Somente com o alvará de 1 ㅇ de abril de 1680, posto em vigor pela Lei de 6 de junho de 1755, houve a edição de norma de defesa dos indígenas, resguardando-se seu livre uso de bens e áreas. Em relação aos colonos humildes, sua ocupação foi reconhecida apenas com a Lei de Terras de 1850, já que, com a interrupção da concessão de sesmarias, por meio da Resolução 76 de 17 de julho de 1822, o método a partir de então empregado para legitimar o vínculo do ocupante à terra passou a ser a posse.

Embora a Lei de Terras tenha previsto a necessidade de reserva de áreas devolutas para os indígenas, não se reconhecia qualquer direito sobre os territórios tradicionalmente por eles ocupados. Tal omissão foi progressivamente reparada, ao menos no que se refere ao campo normativo, com as sucessivas constituições brasileiras, culminando com a de 1988.

$\mathrm{Na}$ seara dos fatos, porém, os conflitos atinentes às terras indígenas são um problema contemporâneo, já que ainda pendente a completa demarcação de suas terras. Tanto assim, que foi necessária a definição do sentido da expressão "terras tradicionalmente ocupadas pelos índios", pelo Tribunal Constitucional, fixando-se como marco temporal a promulgação da atual Constituição. Foi considerado, ainda, caso de "renitente esbulho" a existência, no mesmo marco temporal, de conflito judicial ou de fato sobre a posse da terra. 
Quanto aos povoados, embriões dos atuais centros urbanos, surgiram, inicialmente, de modo concentrado na faixa litorânea, mais favorável à exploração agrícola. Somente no segundo século teve início a penetração para o interior.

No Nordeste, a ocupação dos sertões deu-se, basicamente, com a fixação de currais de gado para atender aos mercados do litoral voltados à indústria açucareira; o interior do extremo Norte brasileiro, por sua vez, teve sua ocupação ditada, principalmente, por expedições destinadas a captura de indígenas e a extração de drogas do sertão, bem como pelas missões católicas destinadas à catequização dos gentios; o Sul, a seu turno, foi voltado ao comércio de gado; e, finalmente, a ocupação do Centro-Oeste, além de Minas Gerais e São Paulo, fundou-se na indústria mineradora, com grandes vazios nas zonas intermédias entre as áreas de origem e os novos focos de ouro, cujo povoamento foi tardio.

Naturalmente, em nenhum dos casos houve uma preocupação sistemática e organizacional com a criação dos povoados, sobretudo, nas áreas de exploração aurífera, onde era curto o tempo que intermediava a notícia da descoberta dos metais e a chegada de pessoas obstinadas à exploração das minas. As ocupações voltaram-se ao atendimento de necessidades circunstanciais, em um desordenado empreendimento capitalista, sem qualquer planejamento político ou econômico.

Não apenas a inexistência de sentido ordenador contribuiu para a desordem dos núcleos constituídos, como também sua própria impossibilidade, ainda que houvesse qualquer intenção nesse sentido, já que o caráter esparso do povoamento aumentava o poder de fato dos proprietários locais, havendo fraca influência das autoridades ligadas ao Governo Central.

Tais fatores geraram caos fundiário e desigualdade ainda não superados no contexto atual e ainda contribuem para a proliferação de conflitos envolvendo posse e propriedade, influenciando na desordem imobiliária existente.

\section{REFERÊNCIAS}

AGHIARIAN, Hércules. Curso de direito imobiliário. 5. ed. Rio de Janeiro: Lumen Juris, 2005.

AMARAL, Antônio José de Azevedo. O estado autoritário e a realidade nacional. São Paulo: Poeteiro Editor Digital, 2014. Disponível em: <http://www.santoandre.sp.gov.br/pesquisa/ebooks/ 366497.PDF>. Acesso em: 24 nov. 2017.

AZEVEDO, Francisco Ferreira dos Santos. Annuario historico, geográfico e descriptivo do estado de Goyaz para 1910. Brasília, SPHAN/8a DR, 1987. 
BERMAN, Harold J. Direito e revolução: a formação da tradição jurídica ocidental. Tradução de Eduardo Takemi Kataoka. São Leopoldo: Unisinos, 2006.

BOURDIEU, Pierre. O poder simbólico. Tradução de Fernando Tomaz. 2. ed. Rio de Janeiro: Bertrand Brasil, 1998.

BRASIL, Constituição da República dos Estados Unidos do Brasil de 24 de fevereiro de 1891. Diário do Congresso Nacional, Rio de Janeiro, 24 fev, 1891, p. 523. Disponível em: <http://www.planalto.gov.br/ccivil_03/Constituicao/Constituicao91.htm>. Acesso em: 19 dez. 2017.

BRASIL, Constituição da República dos Estados Unidos do Brasil de 16 de julho de 1934. Diário Oficial da União, Rio de Janeiro, 16 jul. 1934, Seção 1, Suplemento, p. 1. Disponível em: <http://www.planalto.gov.br/ccivil_03/Constituicao/Constituicao34.htm>. Acesso em: 19 dez. 2017.

BRASIL, Constituição da República Federativa do Brasil de 1967. Diário Oficial da União, Brasília, DF, 24 jan. 1967, Seção 1, p. 953. Disponível em: <http://www.planalto.gov.br/CCivil_03/ Constituicao/Constituicao67.htm>. Acesso em: 19 dez. 2017.

BRASIL, Constituição dos Estados Unidos do Brasil de 10 de novembro de 1937. Diário Oficial da União, Rio de Janeiro, 10 nov. 1937, Seção 1, p. 22.359. Disponível em: <https://www.planalto. gov.br/ccivil_03/constituicao/Constituicao37.htm>. Acesso: em 19 dez. 2017.

BRASIL, Constituição dos Estados Unidos do Brasil de 18 de setembro de 1946. Diário Oficial da União, Rio de Janeiro, 19 set. 1946, Seção 1, p. 13.059. Disponível em: <https://www.planalto.gov.br/ ccivil_03/Constituicao/Constituicao46.htm>. Aceso em: 19 dez. 2017.

BRASIL, Constituição Política do Império do Brazil, de 25 de março de 1824. Coleção de Leis do Império do Brasil, Rio de Janeiro, 1824, Volume 1, p. 7. Disponível em: <https://www.planalto .gov.br/ccivil_03/constituicao/constituicao24.htm>. Acesso em: 18 dez. 2017.

BRASIL, Emenda Constitucional 1 de 17 de outubro de 1969. Diário Oficial da União, Brasília, DF, 20 out. 1969, Seção 1, p. 8.865. Disponível: <https://www.planalto.gov.br/ccivil_03/constituicao/ emendas/emc_anterior1988/emc01-69.htm>. Acesso em: 19 dez. 2017. 
BRASIL, Lei 601 de 18 de setembro de 1850. Dispõe sobre as terras devolutas do Império. Coleção de Leis do Império do Brasil, Rio de Janeiro, 1854, Volume 1, p. 10, pt. II. Disponível em: <http://www.planalto.gov.br/ccivil_03/LEIS/L0601-1850.htm>. Acesso em: 18 dez. 2017.

BRASIL, Resolução 76 de 17 de julho de 1822. Manda suspender a concessão de sesmarias futuras até a convocação da Assembléia Geral Constituinte. Colleç̧ão das Decisões do Governo do Império do Brasil de 1822, Rio de Janeiro: Imprensa Nacional, 1887.

BRASIL, Supremo Tribunal Federal. Segunda Turma. Agravo Regimental no Recurso Extraordinário com Agravo 803.462/MS. Agravante: Tales Oscar Castelo Branco. Agravados: União; Ministério Público Federal; e Fundação Nacional do Índio. Relator: Teori Zavascki. Brasília - DF, 9 de dezembro de 2014. Diário de Justiça Eletrônico de 12 de fevereiro de 2015. Disponível em: <http://redir. stf.jus.br/paginadorpub/paginador.jsp?docTP=TP\&doclD=7734834>. Acesso em: 9 jan. 2018.

BRASIL, Supremo Tribunal Federal. Súmula 650. Diário de Justiça da União, Brasília, DF, de 09 de outubro de 2003, p. 3. Disponível em: <http://www.stf.jus.br/portal/jurisprudencia/menuSumario Sumulas.asp?sumula=1634>. Acesso em: 9 jan. 2018.

BRASIL, Supremo Tribunal Federal. Tribunal Pleno. Petição 3.388/RR. Requerente: Augusto Affonso Botelho Neto. Requerida: União. Relator: Ayres Britto. Brasília - DF, 19 de março de 2009. Diário de Justiça Eletrônico de 25 de setembro de 2009. Disponível em: <http://redir.stf.jus.br/ paginadorpub/paginador.jsp?docTP=AC\&docID=630133>. Acesso em: 9 jan. 2018.

BRUNO, Ernani Silva. História do Brasil: geral e regional. Vol. I: Amazônia. São Paulo: Cultrix, 1967.

. História do Brasil: geral e regional. Vol. II: Nordeste. São Paulo: Cultrix, 1967.

. História do Brasil: geral e regional. Vol. IV: Rio de Minas. São Paulo: Cultrix, 1967.

. História do Brasil: geral e regional. Vol. V: São Paulo e o Sul. São Paulo: Cultrix, 1967.

. História do Brasil: geral e regional. Vol. VI: grande Oeste. São Paulo: Cultrix, 1967.

. História do Brasil: geral e regional. Vol. VII: Brasil (história geral). São Paulo: Cultrix, 1967. 
CARDOSO, Fernando Henrique; FALETTO, Enzo. Dependência e desenvolvimento na América Latina: ensaio de interpretação sociológica. 3. ed. Rio de Janeiro: Zahar Editores, 1975.

DUMONT, Louis. O individualismo: uma perspectiva antropológica da ideologia moderna. Tradução de Álvaro Cabral. Rio de Janeiro: Rocco, 2000.

FAORO, Raymundo. Os donos do poder: formação do patronato político brasileiro. 5. ed. São Paulo: Globo, 2012.

FONSECA, Faustino da. A Descoberta do Brasil. 2. ed. Lisboa: Livraria Central de Gomes de Carvalho, 1908. Disponível em: <https://ia800303.us.archive.org/4/items/descob ertadobras00fons/descobertadobras00fons.pdf >. Acesso em: 5 out. 2019.

FOUCAULT, Michel. Os anormais. Tradução de Eduardo Brandão. São Paulo: Martins Fontes, 2002.

FREYRE, Gilberto. Casa-grande \& senzala: formação da família brasileira sob o regime da economia patriarcal. 48. ed. São Paulo: Global, 2003.

Sobrados e mocambos. 1. ed. digital. São Paulo: Global, 2013.

FURTADO, Celso. Formação econômica do Brasil. 34. ed. São Paulo: Companhia das Letras, 2007.

HESPANHA, Antônio Manuel. Cultura jurídica europeia: síntese de um milênio. Coimbra: Almedina, 1945.

HOLANDA, Sérgio Buarque de. Caminhos e fronteiras. 3. ed. São Paulo: Companhia das Letras, 1994.

Monções. 3. ed. São Paulo: Brasiliense, 2000.

. Raízes do Brasil. 26. ed. São Paulo: Companhia das Letras, 1995.

. Visão do paraíso: os motivos edênicos no descobrimento e colonização do Brasil. São Paulo: Brasiliense; Publifolha, 2000. 
LEITE, Mário. Paulistas e Mineiros: plantadores de cidades. São Paulo: EDART, 1961.

LEROY-BEAULIEU, Paul. De la colonisation chez les peuples modernes. 2. ed. Paris: Guillaumin et cie., 1882.

LIMA, Ruy Cirne. Pequena história territorial do Brasil: sesmarias e terras devolutas. São Paulo: Secretaria de Estado de Cultura, 1990, p. 51.

LOPES, Ana Maria D'Ávila; MATTOS, Karine Rodrigues. O direito fundamental dos indígenas à terra: do Brasil-colônia ao Estado Democrático de Direito. Revista de Informação Legislativa, Brasília, a. 43, n. 170, abr./jun. 2006. Disponível em: <https://www2.senado.leg.br/bdsf/bitstream/ handle/id/92744/Lopes\%20Ana\%20Maria\%20e\%20Mattos\%20Karine. pdf?sequence=1>. Acesso em: 8 jan. 2018.

MARTINS JÚNIOR, José Izidoro. História do Direito Nacional, Rio de Janeiro: Typographia da Empreza Democratica Editora, 1895.

OLIVEIRA VIANNA, Francisco José de. Populações meridionais do Brasil. Rio de Janeiro: Paz e Terra, 1973.

PRADO JÚNIOR, Caio. Formação do Brasil contemporâneo. 16. ed. São Paulo: Brasiliense, 1979.

PRADO, Paulo. Retrato do Brasil: ensaio sobre a tristeza brasileira. 2. ed. São Paulo: IBRASA; INL, 1981.

SCHWARCZ, Lilia Moritz. O espetáculo das raças: cientistas, instituições e questão racial no Brasil. São Paulo : Companhia das Letras, 1993.

SMITH, Adam. A riqueza das nações: investigação sobre sua natureza e suas causas. Vol. II, Livro Quarto. Tradução de Luiz João Baraúna. São Paulo: Nova Cultural Ltda., 1996. Disponível em: <http://www.ie.ufrj.br/intranet/ie/userintranet/hpp/arquivos/051120150019_SMITH1996ariqueza dasnacoesvol.02.pdf>. Acesso em: 24 nov. 2017. 
TODOROV, Tzvetan. Nós e os outros: a reflexão francesa sobre a diversidade humana. Tradução de Sérgio Goes de Paula. Rio de Janeiro: Jorge Zahar, 1993.

TORRES, Alberto. A organização nacional: primeira parte, a Constituição. 3. ed. São Paulo: Ed. Nacional, 1978.

Trabalho enviado em 23 de janeiro de 2019

Aceito em 28 de outubro de 2019 